\title{
ANALISIS BALANCING ROTOR TERHADAP RESIKO KERUSAKAN TURBOCHARGER LOKOMOTIF DIESEL
}

\author{
Ajeng Tyas Damayanti; ajeng@api.ac.id, \\ Politeknik Perkeretaapian Indonesia Madiun, Indonesia
}

\begin{abstract}
Abstrak
Penelitian ini dilakukan dengan tujuan untuk melihat tingkat efektifitas balancing rotor pada komponen turbocharger dan pengaruh balancing rotor terhadap resiko kerusakan turbocharger. Data yang digunakan adalah data primer berupa hasil balancing awal dan akhir rotor turbocharger. Data pelengkap diperoleh dari wawancara dengan teknisi Balaiyasa Yogyakarta akan menunjukkan seberapa besar pengaruh balancing yang telah dilakukan terhadap keseimbangan rotor. Dari hasil pengolahan dan analisis data yang telah dilakukan, diketahui bahwa persentase rata-rata dari efektifitas balancing pada blower sebesar $91,5 \%$, sedangkan persentase rata-rata dari efektifitas balancing pada turbin sebesar 94,5\%. Jadi rata-rata efektifitas balancing baik pada blower maupun turbin adalah sebesar 93\%. Toleransi unbalance yang diizinkan dalam proses balancing adalah 0,56 gram. Apabila unbalance melebihi 0,56 gram maka akan mengakibatkan diantaranya rusaknya bearing akibat turbin dan casing bergesekan dan mengakibatkan resiko retak atau pecah.
\end{abstract}

Kata kunci : balancing rotor, turbocharger, lokomotif diesel

This research aimed to determine the effectiveness of rotor balancing on the turbocharger component and the effect on the risk of turbocharger damage. The primary data were the results of the initial and final balancing of the turbocharger rotor. The supporting data were taken from interviews with BalaiYasa Yogyakarta technicians, which revealed the influence of balancing on the rotor balance. The results of data analysis showed that the average percentage of the balancing effect on the blower was $91.5 \%$, while on the turbine was $94.5 \%$. Thus, the average effectiveness of the blower and turbine balancing was $93 \%$. The unbalance tolerance allowed in the balancing process was 0.56 grams. If the unbalance exceeded 0.56 grams, it would damage bearings due to the turbine and casing rubbed together and causing the risk of cracking or breaking.

Keyword: balancing rotor, turbocharger, diesel locomotive

\section{PENDAHULUAN}

1.1 Latar belakang

Sarana perkeretaapian adalah kendaraan yang bergerak di jalan rel. Salah satu aspek penting yang harus diperhatikan dari sarana adalah perawatan yang dilakukan secara berkala. Salah satu komponen yang sering ditemukan kerusakan yang mengharuskan dilakukan perbaikan berat adalah komponen turbocharger. Turbocharger merupakan komponen yang berfungsi meningkatkan daya dengan memanfaatkan gas buang hasil pembakaran mesin diesel untuk menggerakkan turbin yang dapat meningkatkan tekanan udara untuk proses pembakaran, sehingga tenaga yang dihasilkan menjadi lebih besar.

Banyak hal yang berpengaruh dalam kerusakan komponen turbocharger lokomotif. Dalam proses perawatan turbocharger, rotor turbocharger akan mengalami proses balancing untuk menjaga keseimbangan beban sisi turbin dan kompresor saat berputar. Proses balancing ini akan menganalisis beban tidak seimbang pada turbin dan kompresor yang kemudian salah satu sisi akan dikikir untuk mengurangi beban berlebih pada turbin agar seimbang.

Hadmoko, dkk (2016) mengungkapkan bahwa apabila ketidakseimbangan rotor ini tidak segera ditangani maka akan mengakibatkan kerusakan komponen lainnya seperti cepat ausnya bearing dan kerugian daya yang tentunnya akan mengurangi daya yang dihasilkan. Kualitas balancing rotor akan sangat berpengaruh pada keseimbangan putaran yang dialami turbocharger. Beban yang tidak seimbang akan mengakibatkan putaran turbin menjadi tidak stabil, sehingga dalam jangka waktu tertentu akan mengakibatkan bearing penahan rotor mengalami kerusakan. Kerusakan pada bearing akan mengakibatkan turbocharger berputar tidak stabil dan akan beresiko bergesekan dengan casing. Celah antara turbin dan casing yang sangat kecil memaksa turbin harus berputar sestabil mungkin agar tidak terjadi gesekan permukaan. Apabila turbin bergesekan dengan casing, maka resiko yang ditimbulkan adalah retak hingga pecahnya turbin bahkan casing atau housing turbocharger sehingga hal tersebut dapat mengurangi performa lokomotif. 


\subsection{Tujuan penelitian}

Mengetahui tingkat efektifitas proses balancing rotor pada komponen turbocharger lokomotif diesel saat perawatan maupun perbaikan di Balaiyasa Yogyakarta serta mengetahui pengaruh balancing rotor terhadap resiko kerusakan yang terjadi pada komponen turbocharger lokomotif diesel.

\section{TINJAUAN PUSTAKA}

\subsection{Lokomotif}

Sesuai dengan UU nomor 23 tahun 2007 pasal 96 lokomotif adalah sarana perkeretaapian yang memiliki penggerak sendiri yang bergerak dan digunakan untuk menarik dan/atau mendorong kereta, gerbong dan/atau peralatan khusus antara lokomotif listrik dan lokomotif diesel. Dalam penelitian ini akan fokus pada lokomotif diesel. Lokomotif CC 206 (GE CM20EMP) adalah lokomotif diesel elektrik terbaru milik PT. Kereta Api Indonesia dengan sistem transmisi AC-DC yang diproduksi oleh General Electric Transportation (GE) asal Amerika Serikat. Lokomotif CC 206 datang di Indonesia dan mulai beroperasi berturut-turut pada tahun 2013, 2015, dan 2016 secara bertahap. Secara umum lokomotif CC 206 memiliki spesifikasi 6 gandar dengan berat 90 ton dan beban masing-masing gandar sebesar 15 ton. Lokomotif CC 206 memakai tipe mesin diesel GE 7 FDL-8 EFI versi terbaru yang memiliki tingkat emisi gas buang yang rendah dengan daya sebesar $2250 \mathrm{HP}$. Lokomotif ini juga dilengkapi dengan computer BrighStar $^{T M}$ Sirius yang berfungsi sebagai kontrol utama lokomotif yang dapat dikendalikan melalui Smart Display pada kabin masinis.

Lokomotif CC 203 (GE U20C) adalah lokomotif diesel elektrik dengan susunan gandar Co-Co yang beroperasi di Indonesia sejak tahun 1995. Lokomotif ini dilengkapi dengan mesin diesel tipe GE 7FDL 8 dengan daya sebesar 2150HP dan dilengkapi dengan turbocharger pada mesin diesel. Lokomotif ini bisa dikatakan merupakan hasil pengembangan desain dari lokomotif diesel elektrik sebelumnya, yaitu lokomotif seri CC 201.

Lokomotif CC $201 \quad$ (GE U18C) merupakan lokomotif diesel elektrik buatan General Electric generasi kedua yang digunakan di Indonesia. Lokomotif ini mempunyai 2 boogie masing - masing 3 gandar atau 6 gandar penggerak. Lokomotif ini memakai tipe mesin GE 7FDL 8 dilengkapi turbocharger dengan daya yang dihasilkan sebesar 1950HP. Secara teknis lokomotif CC 201 di Indonesia sebanyak 144 unit dengan rincian 130 unit diantaranya masih beroperasi, 7 unit telah afkir, dan 7 unit lainnya direhab menjadi lokomotif CC 204. Lokomotif ini menjadi seri tertua lokomotif Diesel Elektrik yang masih beroperasi di Indonesia.

\subsection{Turbocharger}

Alfalah, dkk (2017) mengungkapkan bahwa turbocharger didefiniskan sebagai salah satu komponen tambahan pada motor pembakaran dalam baik itu motor bensin maupun motor diesel yang berfungsi untuk meningkatkan mass flow yang masuk ke dalam mesin sehingga tenaga yang dihasilkan dapat meningkat. Komponen utamanya terdiri dari turbin dan kompresor.

Dalam Turbocharger terdapat sebuah turbin axial-flow yang dikendalikan oleh energi gas buang dari sebuah mesin hasil pembakaran sebelum dibuang ke atmosfir. Turbocharger terdiri dari sebuah turbin dan kompresor terpasang pada sebuah batangan (shared shaft). Turbin mengubah panas dan tekanan gas buang menjadi daya putar, yg kemudian digunakan untuk menggerakkan kompresor. Kompresor menggerakkan aliran udara dan memompakannya kedalam intake manifold dengan tekanan yang semakin meningkat. Hal tersebut menghasilkan tekanan udara yang besar untuk memasuki silinder.

Turbocharger tersusun atas beberapa komponen utama dan juga dilengkapi dengan berbagai komponen pendukung. Beberapa komponen diantaranya :
1. Turbin
2. Kompresor
3. Center Housing \& Rotating Assembly (CHRA)
4. Intercooler
5. Wastegates
6. Blow-Off Valve
7. Saluran Pipa

\subsection{Balancing Rotor}

Menurut Hadmoko, dkk (2016) balancing merupakan tindakan menambahkan atau mengurangi massa pada sistem rotor. Pada proses balancing mensyaratkan adanya bahan yang ditambahkan atau dihilangkan dari elemen yang berputar agar mencapai tingkat keseimbangan yang dapat diterima (Bhaskar and Kalmegh, 2012). Hadmoko, dkk (2016) mengatakan apabila keadaaan tidak seimbang pada rotor ini tidak terdeteksi pada tahap permulaan akan mengakibatkan kerusakan struktur pada rotor itu sendiri. Pada proses balancing rotor, perlu diketahui kalibrasi yang dapat menyatakan jumlah ketidakseimbangan serta toleransi 
ketidakseimbangan yang disyaratkan sehingga jumlah massa yang harus dihilangkan atau ditambahkan pada rotor dapat diketahui dengan tepat.

Ketidakseimbangan pada rotor atau komponen seporos dengan rotor yang memiliki pusat gravitasi atau pusat massa dapat beresiko terjadi kapan saja. Menurut Harbintoro, S (2019) gaya rotasi poros yang dihasilkan ditentukan dengan persamaan berikut :

$F$ balance $=m \times e \times \omega^{2}$

Keterangan :

$F$ balance = gaya yang diakibatkan oleh

ketidakseimbangan

$\mathrm{m}=$ berat keseimbangan eksentrisitas rotor

$\mathrm{e}=$ keseimbangan eksentrisitas

$\omega=$ kecepatan poros, $\mathrm{rad} / \mathrm{sec}=2 \pi \mathrm{N} / 60$

$\mathrm{N}=$ kecepatan poros, $\mathrm{RPM}$

Keseimbangan - eksentrisitas merupakan ketidakseimbangan spesifik residu yang ditentukan oleh jumlah ketidakseimbangan yang ada dibagi dengan massa rotor atau komponen terkait. Keseimbangan eksentrisitas yang diizinkan telah dijelaskan dalam ISO 1940-1 : 2003.

TIR = Total Runout yang terindikasi

$$
e=\frac{10 \cdot G}{\frac{n}{1000}}
$$

\section{Keterangan:}

$\mathrm{e}=$ residual eccentricity $(\mu \mathrm{m})$

$\mathrm{G}=$ grade sesuai ISO 1940

$\mathrm{n}=$ putaran kerja rotor $(\mathrm{rpm})$

$$
p=\frac{P \cdot \mathrm{e}}{r}
$$

Keterangan :

$\mathrm{p}=$ maksimum unbalance yang diijinkan (gram)

$\mathrm{P}=$ berat kotor $(\mathrm{kg})$

$\mathrm{r}=$ jari-jari disc rotor $(\mathrm{mm})$ kalibrasi proses balancing awal pada proses sebelum beban berlebih rotor dikurangi. Data kalibrasi proses balancing akhir pada proses setelah beban berlebih rotor dikurangi. Data kuantitatif ini akan dilengkapi dengan data wawancara dengan teknisi Balaiyasa Yogyakarta. Data sekunder berupa Spesifikasi teknis turbocharger lokomotif CC 201, CC 203, dan CC 206, Checksheet perawatan tahunan lokomotif diesel, Checksheet perawatan tahunan turbocharger lokomotif, Manual instruction lokomotif diesel elektrik, Field Service Report (FSR) perbaikan turbocharger lokomotif di Balaiyasa Lokomotif Yogyakarta

\subsection{Metode pengolahan data}

Metode pengolahan data yang digunakan dalam proses penelitian ini menggunakan metode kuantitatif dengan tahapan :

a. Mengumpulkan data primer dan data sekunder.

b. Mengolah data primer menggunakan statistik.

c. Mengolah data sekunder sebagai referensi atau data pendukung.

\subsection{Metode analisis data}

Analisis data dilakukan dengan tahapan sebagai berikut :

a. Menganalisis data dengan cara mendeskripsikan data yang telah terkumpul, baik berupa tabel, grafik, maupun diagram.

b. Perhitungan data dilakukan melalui perhitungan rata-rata dari hasil balancing turbocharger.

c. Hasil balancing turbocharger kemudian akan dianalisis lebih lanjut untuk mengetahui efektifitas balancing rotor.

d. Tingkat efektifitas balancing dapat diketahui melalui perhitungan selisih hasil kalibrasi awal dan hasil kalibrasi akhir setelah rotor dilakukan pengurangan beban unbalance.

e. Pengaruh hasil balancing turbocharger akan dianalisis untuk menentukan sebab akibat dari kualitas balancing terhadap resiko kerusakan turbocharger.

f. Pengambilan kesimpulan dari analisis ini berdasarkan pada hasil perhitungan statistika dilengkapi wawancara ke teknisi Balaiyasa.

\subsection{Lokasi Penelitian \\ Penelitian dilakukan di Balaiyasa Yogyakarta.}

3. METODOLOGI PENELITIAN

2.1. Pengumpulan data Pengumpulan data dilakukan secara primer dan sekunder. Data primer berupa data 
4.1 Langkah-langkah balancing rotor

Langkah-Langkah balancing rotor sebagai berikut :

a) Angkat Rotor Turbin Turbocharger

b) Turbin dibawa menuju ruangan khusus balancing turbocharger

c) Pasang pada mesin balancing

d) Aktifkan mesin balancing

e) Kalibrasi hasil balancing

f) Pengamatan hasil kalibrasi

g) Mengurangi beban berlebih

h) Kalibrasi ulang sampai beban seimbang

i) Lepas dan angkat rotor turbin dari mesin

\subsection{Hasil Balancing Turbocharger}

Hasil balancing turbocharger merupakan data perbandingan hasil awal sebelum dilakukan balancing dan hasil akhir setelah dilakukan balancing pada turbocharger. Hasil akhir yang diperhatikan adalah massa pada blower dan turbin yang diharapkan dapat seimbang. Sehingga massa blower akan ikut berkurang dan keduanya akan mencapai titik yang hampir seimbang. Berdasarkan buku Manual Instruction dari General Electric, toleransi perhitungan yang diizinkan sesuai manual instruction adalah 0,03 inci ons atau setara dengan 0,5 gr.

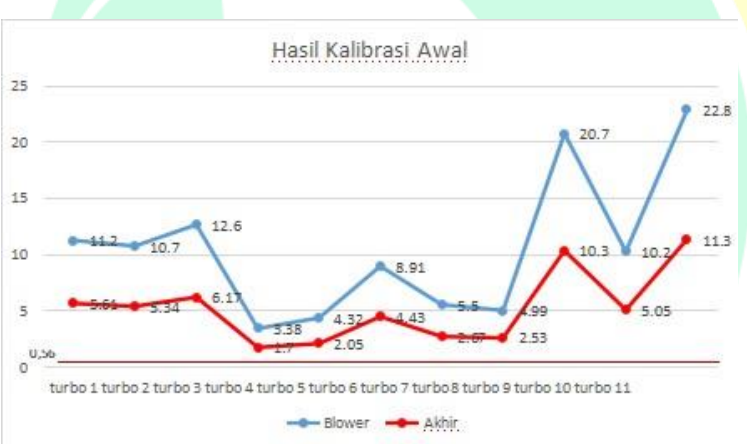

Gambar 1 Hasil kalibrasi awal

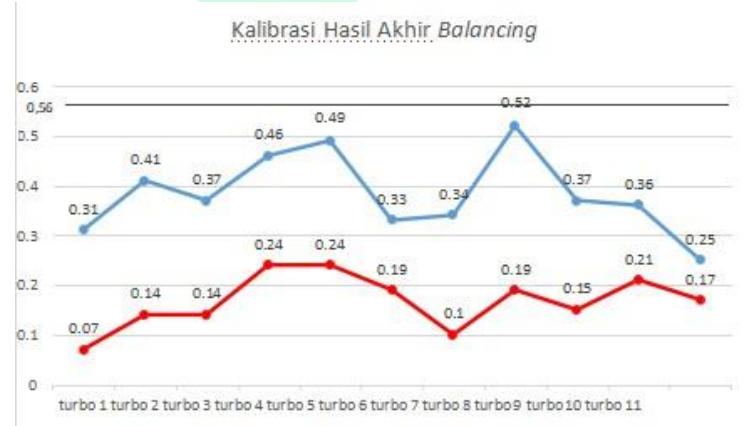

$\rightarrow$ Blower $\rightarrow$ Turbin

Gambar 2 Hasil kalibrasi akhir
Data efektifitas balancing rotor merupakan hasil perhitungan selisih kalibrasi awal dan kalibrasi akhir. Hasil kalibrasi diperoleh saat dilakukan pengecekan unbalance pada rotor menggunakan mesin balancing. Efektifitas balancing menunjukkan besarnya selisih unbalance rotor awal dan setelah dilakukan pengurangan beban berlebih, angka tersebut dapat mengetahui tingkat efektifitas dalam proses balancing

Tabel 1 Efektifitas balancing rotor

\begin{tabular}{|c|c|c|c|c|c|c|}
\hline \multirow[t]{2}{*}{ KOMPONEN } & \multicolumn{3}{|c|}{ BLOWER } & \multicolumn{3}{|c|}{ TURBN } \\
\hline & AWAL & AKHIR & Efektifitas & AWAL & AKHIR & Efektifitas \\
\hline $\begin{array}{c}\text { TURBO 1 } \\
\text { EX CC 2030201 }\end{array}$ & $11,2 \mathrm{gr}$ & $0,319 \mathrm{gr}$ & $10,881 \mathrm{gr}$ & $5,61 \mathrm{gr}$ & $0,07 \mathrm{gr}$ & $5,54 \mathrm{gr}$ \\
\hline $\begin{array}{c}\text { TURBO } 2 \\
\text { EX CC } 2040305\end{array}$ & $10,7 \mathrm{gr}$ & $0,41 \mathrm{gr}$ & $10,29 \mathrm{gr}$ & $5,34 \mathrm{gr}$ & $0,14 \mathrm{gr}$ & $5,20 \mathrm{gr}$ \\
\hline $\begin{array}{c}\text { TURBO } 3 \\
\text { EXCC } 2017718\end{array}$ & $12,6 \mathrm{gr}$ & $0,37 \mathrm{gr}$ & $12,23 \mathrm{gg}$ & $6,17 \mathrm{gr}$ & $0,14 \mathrm{gr}$ & $6,03 \mathrm{gr}$ \\
\hline $\begin{array}{c}\text { TURBO } 4 \\
\text { EXCC } 2018317\end{array}$ & $3,38 \mathrm{gr}$ & $0,46 \mathrm{gr}$ & $2,29 \mathrm{gr}$ & $1,70 \mathrm{gr}$ & $0,24 \mathrm{gr}$ & $1,46 \mathrm{gr}$ \\
\hline $\begin{array}{c}\text { TURBO } 5 \\
\text { EXCC 2040302 }\end{array}$ & $4,32 \mathrm{gr}$ & $0,49 \mathrm{gr}$ & $3,38 \mathrm{gr}$ & $2,05 \mathrm{gr}$ & $0,24 \mathrm{gr}$ & $1,81 \mathrm{gr}$ \\
\hline $\begin{array}{c}\text { TURBO } 6 \\
\text { EX CC } 2019207\end{array}$ & $8,91 \mathrm{gr}$ & $0,33 \mathrm{gr}$ & $8,58 \mathrm{gr}$ & $4,43 \mathrm{gr}$ & $0,19 \mathrm{gr}$ & $4,24 \mathrm{gr}$ \\
\hline $\begin{array}{c}\text { TURBO } 7 \\
\text { EXCC } 2018901\end{array}$ & $5,50 \mathrm{gr}$ & $0,34 \mathrm{gr}$ & $5,16 \mathrm{gr}$ & $2,67 \mathrm{gr}$ & $0,10 \mathrm{gr}$ & $2,57 \mathrm{gr}$ \\
\hline $\begin{array}{c}\text { TURBO 8 } \\
\text { EXCC } 2018329\end{array}$ & $4,99 \mathrm{gr}$ & $0,52 \mathrm{gr}$ & $4,47 \mathrm{gr}$ & $2,53 \mathrm{gr}$ & $0,19 \mathrm{gr}$ & $2,34 \mathrm{gr}$ \\
\hline $\begin{array}{c}\text { TURBO 9 } \\
\text { EXCC } 2018316\end{array}$ & $20,7 \mathrm{gr}$ & $0,37 \mathrm{gr}$ & $20,33 \mathrm{gr}$ & $10,3 \mathrm{gr}$ & $0,19 \mathrm{gr}$ & $10,11 \mathrm{gr}$ \\
\hline $\begin{array}{c}\text { TURBO } 10 \\
\text { EXCC } 2018314\end{array}$ & $10,2 \mathrm{gr}$ & $0,36 \mathrm{gr}$ & $9,84 \mathrm{gr}$ & $5,05 \mathrm{gr}$ & $0,21 \mathrm{gr}$ & $4,84 \mathrm{gr}$ \\
\hline $\begin{array}{c}\text { TURBO } 11 \\
\text { EXCC } 2061312\end{array}$ & $22,8 \mathrm{gr}$ & $0,25 \mathrm{gr}$ & $22,55 \mathrm{gr}$ & $11,3 \mathrm{gr}$ & $0,17 \mathrm{gr}$ & $11,13 \mathrm{gr}$ \\
\hline
\end{tabular}

\subsection{Efektifitas Balancing Rotor}


Tabel 2 Persentase efektifitas blower

\begin{tabular}{|c|c|c|c|c|}
\hline Komponen & Efeltifitas & Awal & Rumus perhitungan & Persentase \\
\hline $\begin{array}{c}\text { TURBO 1 } \\
\text { EXCC } 2030201\end{array}$ & $10,881 \mathrm{gr}$ & $11,2 \mathrm{gr}$ & $\mathrm{n}=\frac{10,881}{11,2} \times 100 \%$ & $97 \%$ \\
\hline $\begin{array}{c}\text { TURBO 2 } \\
\text { EXCC } 2040305\end{array}$ & $10,29 \mathrm{gr}$ & $10,7 \mathrm{gr}$ & $\mathrm{n}=\frac{10,29}{10,7} \times 100 \%$ & $96 \%$ \\
\hline $\begin{array}{c}\text { TURBO 3 } \\
\text { EX CC } 2017718\end{array}$ & 12,23 gr & $12,6 \mathrm{gr}$ & $\mathrm{n}=\frac{12,23}{12,6} \times 100 \%$ & $97 \%$ \\
\hline $\begin{array}{c}\text { TURBO } 4 \\
\text { EXCC } 2018317\end{array}$ & $2,29 \mathrm{gr}$ & 3,38 gr & $\mathrm{n}=\frac{2,29}{3,38} \times 100 \%$ & $68 \%$ \\
\hline $\begin{array}{c}\text { TURBO 5 } \\
\text { EXCC } 2040302\end{array}$ & $3,38 \mathrm{gr}$ & 4,32 gr & $\mathrm{n}=\frac{3,38}{4,32} \times 100 \%$ & $78 \%$ \\
\hline $\begin{array}{c}\text { TURBO } 6 \\
\text { EXCC } 2019207\end{array}$ & $8,58 \mathrm{gr}$ & $8,91 \mathrm{gr}$ & $\mathrm{n}=\frac{8,58}{8,91} \times 100 \%$ & $96 \%$ \\
\hline $\begin{array}{c}\text { TURBO 7 } \\
\text { EXCC } 2018901\end{array}$ & $5,16 \mathrm{gr}$ & $5,50 \mathrm{gr}$ & $\mathrm{n}=\frac{5,16}{5,50} \times 100 \%$ & $94 \%$ \\
\hline $\begin{array}{c}\text { TURBO } 8 \\
\text { EX CC } 2018329\end{array}$ & $4,47 \mathrm{gr}$ & $4,99 \mathrm{gr}$ & $\mathrm{n}=\frac{4,47}{4,99} \times 100 \%$ & $89 \%$ \\
\hline $\begin{array}{c}\text { TURBO 99 } \\
\text { EX CC } 2018316\end{array}$ & 20,33 gr & $20,7 \mathrm{gr}$ & $\mathrm{n}=\frac{20,33}{20,7} \times 100 \%$ & $98 \%$ \\
\hline $\begin{array}{c}\text { TURBO } 10 \\
\text { EXCC } 2018314\end{array}$ & $9,84 \mathrm{gr}$ & $10,2 \mathrm{gr}$ & $\mathrm{n}=\frac{9,84}{10,2} \times 100 \%$ & $96 \%$ \\
\hline $\begin{array}{c}\text { TURBO } 11 \\
\text { EX CC 206 } 1312\end{array}$ & $22,55 \mathrm{gr}$ & 22,8 gr & $\mathrm{n}=\frac{22,55}{22,8} \times 100 \%$ & $98 \%$ \\
\hline
\end{tabular}

Tabel 3 Persentase efektifitas turbin

\begin{tabular}{|c|c|c|c|c|}
\hline Komponen & Efeltifitias & Awal & Rumus perhitungan & Persentase \\
\hline $\begin{array}{c}\text { TURBO 1 } \\
\text { EX CC 203 02 01 }\end{array}$ & $5,54 \mathrm{gr}$ & $5,61 \mathrm{gr}$ & $\mathrm{n}=\frac{5,54}{5,61} \times 100 \%$ & $98 \%$ \\
\hline $\begin{array}{c}\text { TURBO 2 } \\
\text { EX CC } 2040305\end{array}$ & $5,20 \mathrm{gr}$ & $5,34 \mathrm{gr}$ & $\mathrm{n}=\frac{5,20}{5,34} \times 100 \%$ & $97 \%$ \\
\hline $\begin{array}{c}\text { TURBO 3 } \\
\text { EX CC } 2017718\end{array}$ & $6,03 \mathrm{gr}$ & $6,17 \mathrm{gr}$ & $\mathrm{n}=\frac{6,03}{6,17} \times 100 \%$ & $97 \%$ \\
\hline $\begin{array}{c}\text { TURBO 4 } \\
\text { EX CC } 2018317\end{array}$ & $1,46 \mathrm{gr}$ & $1,70 \mathrm{gr}$ & $\mathrm{n}=\frac{1,46}{1,70} \times 100 \%$ & $85 \%$ \\
\hline $\begin{array}{c}\text { TURBO } 5 \\
\text { EX CC } 2040302\end{array}$ & $1,81 \mathrm{gr}$ & $2,05 \mathrm{gr}$ & $\mathrm{n}=\frac{1,81}{2,05} \times 100 \%$ & $88 \%$ \\
\hline $\begin{array}{c}\text { TURBO } 6 \\
\text { EX CC } 2019207\end{array}$ & $4,24 \mathrm{gr}$ & 4,43 gr & $\mathrm{n}=\frac{4,24}{4,43} \times 100 \%$ & $95 \%$ \\
\hline $\begin{array}{c}\text { TURBO 7 } \\
\text { EX CC } 2018901\end{array}$ & $2,57 \mathrm{gr}$ & $2,67 \mathrm{gr}$ & $\mathrm{n}=\frac{2,57}{2,67} \times 100 \%$ & $96 \%$ \\
\hline $\begin{array}{c}\text { TURBO } 8 \\
\text { EX CC } 2018329\end{array}$ & $2,34 \mathrm{gr}$ & $2,53 \mathrm{gr}$ & $\mathrm{n}=\frac{2,34}{2,53} \times 100 \%$ & $92 \%$ \\
\hline $\begin{array}{c}\text { TURBO } 9 \\
\text { EX CC } 2018316\end{array}$ & $10,11 \mathrm{gr}$ & 10,3 gr & $\mathrm{n}=\frac{10,11}{10,3} \times 100 \%$ & $98 \%$ \\
\hline $\begin{array}{c}\text { TURBO } 10 \\
\text { EX CC } 2018314\end{array}$ & $4,84 \mathrm{gr}$ & $5,05 \mathrm{gr}$ & $n=\frac{4,84}{5,05} \times 100 \%$ & $95 \%$ \\
\hline $\begin{array}{c}\text { TURBO } 11 \\
\text { EX CC } 2061312\end{array}$ & $11,13 \mathrm{gr}$ & 11,3 gr & $\mathrm{n}=\frac{11,13}{11,3} \times 100 \%$ & $98 \%$ \\
\hline
\end{tabular}

\section{PERSENTASE EFEKTIFITAS B.ALANCING ROTOR}

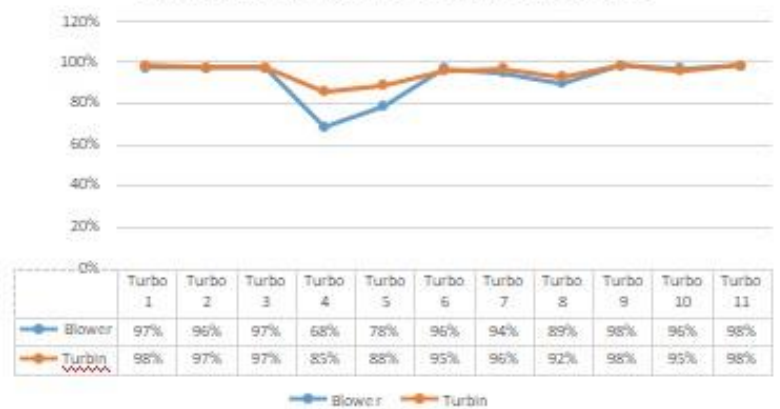

Gambar 3 Persentase efektifitas balancing rotor

Rata-rata efektifitas blower $=91,5 \%$

Rata-rata efektifitas turbin $=94,5 \%$

Rata-rata efektifitas balancing

$=$ (efektifitas blower + efektifitas turbin $)$

$$
\begin{aligned}
& 100 \% \\
& =\frac{(91,5+94,5)}{2} \times 100 \% \\
& =93 \%
\end{aligned}
$$

Berdasarkan data tabel dan grafik diatas, maka persentase rata-rata yang diperoleh dari efektifitas balancing pada blower sebesar 91,5\%, sedangkan persentase rata-rata yang diperoleh dari efektifitas balancing pada turbin sebesar $94,5 \%$. Sehingga dari persentase tersebut dapat diperoleh angka bahwa efektifitas balancing baik pada blower maupun turbin sebesar $93 \%$.

4.4 Pengaruh Balancing Turbocharger terhadap resiko kerusakan

Salah satu pengaruh besar dalam kerusakan turbocharger adalah hasil balancing rotor turbocharger pada saat dilakukan perawatan maupun perbaikan. Keseimbangan putaran rotor akan berpengaruh pada kestabilan putaran turbin saat turbocharger bekerja. Tingginya putaran turbin dan celah yang sempit antara turbin dan housing menuntut rotor berputar dengan stabil untuk menghindari gesekan yang terjadi antara turbin dan housing.

Ketidakseimbangan bisa terjadi pada turbin yang pusat massanya tidak bertepatan dengan pusat geometris dari poros rotor. Besar massa dan titik koordinat letak ketidakseimbangan tersebut dapat ditentukan dengan memutar rotor pada kecepatan konstan lalu mengukur reaksi getaran yang timbul. 
Tabel 4 Data teknis rotor

\begin{tabular}{|c|l|l|l|}
\hline No & \multicolumn{2}{|c|}{ Data teknis } & Satuan \\
\hline 1. & $\begin{array}{l}\text { Putaran kerja } \\
\text { rotor }\end{array}$ & 1200 & $\mathrm{n} /$ menit \\
\hline 2. & Berat rotor & 28 & $\mathrm{~kg}$ \\
\hline 3. & $\begin{array}{l}\text { Diameter disc } \\
\text { rotor }\end{array}$ & 334,5 & $\mathrm{~mm}$ \\
\hline 4. & $\begin{array}{l}\text { Radius disc } \\
\text { rotor }\end{array}$ & 167,25 & $\mathrm{~mm}$ \\
\hline
\end{tabular}

Proses balancing rotor yang dilakukan menggunakan Balance Quality Grade (G) berdasarkan ISO 1940-1 : 2003, yaitu dengan Grade sebesar 0,4.

\section{Residual eccentricity (e) :}

$$
\begin{aligned}
& e=\frac{10 . G}{n / 1000} \\
& e=\frac{10.0,4}{1200 / 1000} \\
& e=3,33 \mu \mathrm{m}
\end{aligned}
$$

Maximum permissible unbalance $(p)$ :

$$
\begin{aligned}
& p=\frac{P \cdot e}{r} \\
&=\frac{28 \cdot 3,33}{167,25} \\
&=0,5575 \mathrm{gram} \\
& \approx 0,56 \mathrm{gram}
\end{aligned}
$$

Maximum permissible unbalance adalah batas toleransi ketidakseimbangan berat yang diizinkan pada rotor dalam proses balancing. Sesuai hasil perhitungan diatas maka toleransi selisih berat yang diizinkan maksimal dibulatkan menjadi 0,56 gram. Apabila lebih dari angka yang diizinkan, maka rotor turbocharger harus dilakukan balancing ulang dan mengurangi berat berlebihnya sampai memenuhi syarat.

\subsection{Hasil wawancara teknisi}

Hasil wawancara ini akan melengkapi analisis statistik yang telah dilakukan. Dari hasil wawancara dengan teknisi diperoleh hasil sebagai berikut :

a) Kerusakan turbocharger terjadi pada komponen dan kerusakan yang seringkali terjadi adalah sebagai berikut :

1. Casing retak/pecah

2. Nozzle ring retak/pecah

3. Turbin retak/pecah

4. Kerusakan bearing

5. Putaran rotor tidak stabil

6. Gagal fungsi turbo

b) Balancing rotor pada turbocharger saat perawatan dan perbaikan penting dilakukan dengan tujuan :

1. Untuk menyeimbangkan beban, sehingga rotor dapat berputar dengan stabil.

2. Untuk menentukan kestabilan rotor karena beban berlebih.

3. Agar rotor dapat berputar stabil dalam putaran tinggi.

c) Bagaimanakah cara agar balancing rotor dapat menghasilkan kualitas yang baik dalam perawatan dan perbaikan :

1. Diperlukan ketelitian teknisi yang bekerja.

2. Teknisi harus sabar dan teliti menganalisis bagian turbin yang kelebihan beban.

3. Perlahan mengurangi beban berlebih, proses dilakukan berulang-ulang hingga hasil maksimal

d) Apa hubungan dan pengaruh kualitas balancing Turbocharger terhadap resiko kerusakan komponen.

1. Rotor yang berputar tidak stabil menyebabkan resiko turbin bergesekan dengan casing.

2. Gesekan dapat menimbulkan keretakan, pecahnya turbin/casing

3. Dalam jangka waktu tertentu menyebabkan kerusakan bearing karena menumpu putaran yang tidak stabil.

Berdasarkan hasil wawancara diatas, diketahui bahwa proses balancing rotor penting dilakukan agar performa turbocharger berjalan dengan baik. Diperlukan ketelitian perawat sarana dalam menemukan bagian turbin yang mengalami kelebihan beban serta mengurangi beban tersebut. Perawat sarana juga mengetahui apa dampak yang ditimbulkan apabila balancing tidak dilakukan dengan benar.

\section{KESIMPULAN DAN SARAN}

\subsection{Kesimpulan}

Dari hasil pembahasan yang telah dilakukan mengenai pengaruh proses Balancing Rotor terhadap resiko kerusakan Turbocharger 
lokomotif diesel elektrik dengan studi kasus di Balai Yasa Lokomotif Yogyakarta, dapat disimpulkan :

a. Kualitas proses balancing rotor Turbocharger di Balai Yasa Yogyakarta, adalah sebagai berikut :

1) Tingkat efektifitas balancing pada sisi turbin sebesar $94 \%$.

2) Tingkat efektifitas balancing pada sisi blower sebesar $91,5 \%$.

Dalam satu tahun, rata-rata tingkat efektifitas balancing rotor turbocharger yaitu sebesar 93\%. Sehingga, dapat disimpulkan bahwa balancing turbo telah dilakukan dengan baik.

b. Hasil analisis untuk menentukan pengaruh balancing terhadap resiko kerusakan turbocharger, sebagai berikut :

1) Dengan efektifitas balancing rotor yang sangat baik dengan persentase 93\% serta resiko kerusakan akibat pengaruh rotor turbin dalam satu tahun sebesar 46\%. maka dapat disimpulkan bahwa pengaruh kualitas balancing rotor relatif kecil terhadap resiko kerusakan yang ditimbulkan.

2) Berdasarkan hasil perhitungan balancing maka didapatkan nilai toleransi unbalance adalah 0,56 gram.

3) Berdasarkan hasil wawancara diperoleh hasil unbalance rotor melebihi batas toleransi akan mengakibatkan beberapa hal seperti rusaknya bearing dalan jangka waktu yang lama, putaran tidak stabil sehingga turbin dan casing akan bergesekan.

\subsection{Saran}

Berdasarkan kesimpulan yang telah didapat maka terdapat beberapa saran yang dapat diberikan untuk memperbaiki kajian ini, antara lain:

a. Perlu adanya analisis lebih menyeluruh dan lengkap terkait berbagai kerusakan yang terjadi pada turbocharger lokomotif diesel elektrik, untuk mengetahui penyebabpenyebab yang mempengaruhi kerusakan turbocharger beserta solusinya, agar persentase kerusakan dapat menurun.

b. Teknisi perlu lebih teliti dan selalu beracuan pada Manual Instruction yang berlaku dalam proses Balancing Turbocharger agar kualitas balancing lebih baik dan lebih efektif. c. Perlu adanya perkembangan teknologi untuk Balancing Rotor agar proses balancing lebih akurat dan teliti, tidak hanya bergantung pada ketelitian tenaga teknisi di lapangan, agar kerusakan turbocharger akibat unbalance rotor dapat diminalisir.

\section{DAFTAR PUSTAKA}

Alfalah, W., Sulistyo, E., Ikhsan, R.. 2017. Pengaruh Pemeliharaan Overhaul Turbocharger Terhadap Kinerja Mesin Unit VII PLTD Ampenan. Jakarta: Jurusan Teknik Mesin Sekolah Tinggi Teknik PLN.

General Electric. (2012). Manual Instruction C20-EMP GEK-80343 Volume 3. Amerika: General Electric Transportation.

General Electric. (2013). Manual Instruction Module 10 Turbocharger. Amerika: General Electric Transportation.

https://artikelteknologi.com/komponen-komponen turbocharger/2/. Diakses pada tanggal 2 Desember 2019.

Hadmoko, T., Widodo, A., Satrijo, D., (2016). Balancing Rotor Dengan Analisis Sinyal Getaran Dalam Kondisi Steady State. Semarang: Jurusan Teknik Mesin, Fakultas Teknik Universitas Diponegoro.

Harbintoro, S. (2019). Metode Keseimbangan Bidang Tunggal Pada Proses Balancing Komponen Boiler Feed Pump Rotor. Bandung : Balai Besar Logam dan Mesin.

Kalmegh, A and Bhaskar, S. (2012). Dynamic Balancing of Cnetrifugal Pump Impeller. International Journal of Emerging Technology and Advanced Engineering. Vol.2, issue 6, June 2012.

PP No. 6 Tahun 2017, Penyelenggaraan Perkeretaapian.

UU No. 23 Tahun 2007, Perkeretaapian. 